\title{
The effect of Helicobacter pylori infection on the decline of lung function in a health screening population
}

\author{
Ha Youn Lee ${ }^{1}$, Hye-Rin Kang ${ }^{2}$, Jung-Kyu Lee ${ }^{3}$, Eun Young Heo ${ }^{3}$, Seung Ho Choi ${ }^{4}$, Deog Kyeom Kim ${ }^{3}$ \\ ${ }^{1}$ Division of Pulmonary, Department of Internal Medicine, Serim General Hospital, Incheon, Korea; ${ }^{2}$ Division of Pulmonary and Critical Care \\ Medicine, Department of Internal Medicine, Veterans Health Service Medical Center, Seoul, Korea; ${ }^{3}$ Division of Pulmonary and Critical Care \\ Medicine, Department of Internal Medicine, Seoul Metropolitan Government-Seoul National University Boramae Medical Center, Seoul, Korea; \\ ${ }^{4}$ Department of Internal Medicine and Healthcare Research Institute, Healthcare System Gangnam Center, Seoul National University Hospital, \\ Seoul, Korea \\ Contributions: (I) Conception and design: DK Kim; (II) Administrative support: SH Choi; (III) Provision of study materials or patients: H Kang, \\ SH Choi; (IV) Collection and assembly of data: HY Lee, H Kang, EY Heo; (V) Data analysis and interpretation: HY Lee, JK Lee, DK Kim; (VI) \\ Manuscript writing: All authors; (VII) Final approval of manuscript: All authors. \\ Correspondence to: Deog Kyeom Kim, MD, PhD. Division of Pulmonary and Critical Care Medicine, Department of Internal Medicine, Seoul \\ Metropolitan Government-Seoul National University Boramae Medical Center, \#395 Shindaebang-2-Dong, Dongjak-Gu, Seoul, 156-707, Korea. \\ Email: kimdkmd@snu.ac.kr; Seung Ho Choi. Department of Internal Medicine and Healthcare Research Institute, Healthcare System Gangnam \\ Center, Seoul National University Hospital, Seoul, Korea. Email: cshmed@snuh.org.
}

Background: Although Helicobacter pylori (H. pylori) infection has long been associated with many extragastric diseases, its long-term effects on declining lung function and the development of chronic obstructive pulmonary disease (COPD) remains controversial.

Methods: We conducted a retrospective study in a health screening population (Gene-Environment of Interaction and Phenotype Cohort at Seoul National University Gangnam Health Center in Korea) recruited from 2004 to 2015. The annual decline rates of lung function and the risk for COPD were compared to the seropositivity for $H$. pylori. We also assessed the impact of the $H$. pylori eradication treatment on lung function.

Results: Among 3,619 subjects, 1,849 subjects (51.1\%) tested positive for H. pylori-specific IgG. In the first year, 95 (2.6\%) patients were diagnosed with COPD. however, there was no difference in seropositivity for H. pylori in patients with COPD compared to non-COPD subjects $(\mathrm{P}=0.756)$. There was no significant difference in the incidence of COPD between the seronegative $(2.2 \%)$ and the seropositive group $(2.0 \%$; $\mathrm{P}=0.728$ ) even during the follow-up period. The decline rates of the mean $\mathrm{FVC}$ and $\mathrm{FEV}_{1}$ were not different between the seronegative and seropositive group (35.38 vs. $34.34 \mathrm{~mL} /$ year for FVC, $\mathrm{P}=0.389 ; 39.23$ vs. $37.49 \mathrm{~mL} /$ year for $\mathrm{FEV}_{1}, \mathrm{P}=0.086$ ). The eradication treatment for $H$. pylori did not affect the decline rates of mean $\mathrm{FVC}$ and $\mathrm{FEV}_{1}$.

Conclusions: Infection or eradication treatment of $H$. pylori was not associated with the decline of lung function or COPD progression in this general population health screening. As a result, H. pylori may not be a significant contributor to deteriorating lung function.

Keywords: Helicobacter pylori (H. pylori); chronic obstructive pulmonary disease (COPD); spirometry

Submitted Mar 30, 2020. Accepted for publication Jun 28, 2020.

doi: 10.21037/apm-20-850

View this article at: http://dx.doi.org/10.21037/apm-20-850

\section{Introduction}

Helicobacter pylori (H. pylori) is the leading cause of several gastric diseases, including superficial gastritis, peptic ulcer disease, mucosa-associated lymphoid tissue lymphoma, and gastric adenocarcinoma. Since reports indicated that H. pylori infection was associated with coronary heart 
disease (1), subsequent epidemiological studies also associated $H$. pylori infection with extra-gastric diseases, such as cardiovascular, neurologic, hematologic, allergic, metabolic, and other diseases (2-4).

However, the relationship between chronic obstructive pulmonary disease (COPD) and $H$. pylori infection remains controversial. A previous study demonstrated that patients with chronic bronchitis tested significantly higher for $H$. pylori seropositivity than controls $(83.3 \%$ vs. $60 \% ; \mathrm{P}=0.007)(5)$. Additionally, the rate of $\mathrm{H}$. pylori seropositivity was reported to be higher in patients with COPD than in controls $(54.7 \%$ of 58 patients with COPD, $23.5 \%$ of 17 controls ( $\mathrm{P}=0.026)$ (6).

Recently, large epidemiological studies have shown an association between $H$. pylori seropositivity and COPD. Specifically, previous findings revealed that $H$. pylori $\mathrm{IgG}$ levels correlated with the severity of COPD (7). Conversely, a population-based cross-sectional study reported no association between $H$. pylori exposure and COPD, measures of allergic disease, or decline in lung function (8). These results support our previous study of a population with high $H$. pylori infection rates that demonstrated no relationship between COPD and $H$. pylori seropositivity (9). However, a meta-analysis that consisted of 16 studies suggested that $H$. pylori infection was associated with an increased risk of COPD [odds ratio (OR) 2.07, 95\% CI: 1.81-2.36, $\mathrm{P}=0.05](10)$.

Since $H$. pylori infection rates vary by geographic area, age, and ethnicity, we conducted a large-scale longitudinal data analysis in Korea where H. pylori infection is prevalent. Herein we investigated the relationship between $H$. pylori infection and the rate of lung function decline, including the risk for COPD. In addition, we evaluated the impacts of medical eradication of $H$. pylori on lung function decline and the risk of COPD to further clarify the relationships.

We present the following article in accordance with the STROBE reporting checklist (available at http://dx.doi. org/10.21037/apm-20-850).

\section{Methods}

\section{Patients and data}

We conducted this retrospective cohort study using the Gene-Environment of Interaction and phenotype (GENIE) data. The GENIE cohort consisted of participants who had visited Seoul National University Gangnam Center in South Korea for health checkups, agreed to participate in genetic studies, and donated blood samples (11).

Data were obtained from 2004 to 2015 in adults at least 40 years old, and the clinical information was collected including age, sex, height, weight, comorbidities, smoking status, spirometric and laboratory data, and esophagogastroduodenoscopy (EGD) results. Spirometry and $H$. pylori-specific IgG concentrations were measured annually for up to 12 years. Smoking-related variables were obtained by questionnaire. Patients who had undergone at least one $H$. pylori IgG test and who had spirometry for more than two years were included in the study. We excluded patients who were diagnosed with lung cancer during the follow-up period or who underwent pulmonary resection. Spirometry was performed according to the standard guidelines of the American thoracic society (12).

H. pylori-specific IgG concentrations were measured using two different tests depending on the study year. A commercially available enzyme-linked immunosorbent assay (RADIM, Pomezia-Rome, Italy) was used according to the manufacturer's protocol prior to April 2013. We included only positive $(\geq 30 \mathrm{U} / \mathrm{mL})$ or negative $(<15 \mathrm{U} / \mathrm{mL})$ results in this analysis excluding equivocal results $(15-30 \mathrm{U} / \mathrm{mL})$. H. pylori-specific IgG concentrations were measured with HPG kits (Immulite 2000 Chemiluminescent Microparticle Immuno Assay SIEMENS, UK) from April 2013 until the end of the study. H. pylori IgG levels higher than $1.10 \mathrm{IU} / \mathrm{mL}$ were regarded as positive, and values that ranged from 0 to $0.9 \mathrm{IU} / \mathrm{mL}$ were considered negative in the Immulite 2000 assay. We defined a recently infected person as a subject whose $H$. pylori-specific IgG value changed from negative to positive during the follow-up period.

\section{Outcome measures}

Using the baseline $H$. pylori-specific IgG concentrations, we determined whether $H$. pylori seropositivity was associated with the incidence or development of COPD. COPD was defined as a prebronchodilator $\mathrm{FEV}_{1}$ /forced vital capacity (FVC) ratio of $<0.7$. We also compared the annual $\mathrm{FEV}_{1}$ or FVC reduction rates of seropositive and seronegative subjects.

Moreover, the difference in the rate of decline in pulmonary function of seropositive patients was evaluated by stratifying the patients into two groups: (I) the H. pyloritreated group and (II) the non-treated group. The treated group included the patients who completed the course of eradication regimen drugs such as a proton pump inhibitor (PPI), clarithromycin, and amoxicillin. 
A subject whose $H$. pylori-specific Ig $G$ value changed from negative to positive during the follow-up period was defined as a recently infected person.

\section{Statistical analysis}

Data are presented as the mean \pm standard deviations (SDs) for continuous, normally distributed variables or medians with interquartile ranges (IQRs) for non-normally distributed variables. Categorical variables were analyzed using the chi-square test, and a $t$-test was used to compare the differences between normally distributed, continuous data. $\mathrm{P}<0.05$ (two-tailed) was considered statistically significant. A random intercept and random slope model were used to estimate the annual lung function decline. The data were adjusted for multiple covariates, including age, sex, height, and smoking pack-year. We performed statistical analyses using STATA software version 15.0 (StataCorp, College Station, TX, USA).

\section{Ethical statement}

The present study was approved by the Institutional review board (IRB No. H-1804-028-934) and was in accordance with the 1964 and later modifications of the Helsinki declaration (as revised in 2013) on the use of human subjects for research. Written informed consent was obtained from the patient before GENIE cohort registration.

\section{Results}

A total of 3,843 patients were followed-up for 2-12 years (median follow-up, 7 years; IQR, 5-9). Among these participants, 224 subjects $(5.83 \%)$ were excluded due to equivocal $H$. pylori IgG tests. Therefore, we included 3,619 subjects in our analysis. The baseline characteristics of the study subjects are presented in Table 1 . The mean age of patients was 48.57 years; $2,226(61.5 \%)$ were men, and $602(16.7 \%)$ were current smokers. The mean $\mathrm{FEV}_{1}$ was $3.13 \pm 0.66 \mathrm{~L}(104.2 \%$ of the predicted value), and the mean FVC was $3.86 \pm 0.82 \mathrm{~L}(96.66 \%$ of the predicted value). Further, 1,849 (51.1\%) patients were seropositive, and $1,770(48.9 \%)$ were seronegative according to the first serology test.

\section{H. pylori infection and prevalence of COPD}

The initial spirometry revealed that a total of 95 (2.6\%) patients had COPD; however, the prevalence of COPD did not differ according to the seropositivity for $\mathrm{H}$. pylori (2.5\% in seropositive group vs. $2.7 \%$ in seronegative group; $\mathrm{P}=0.756)$. Although 76 patients $(2.1 \%)$ were newly diagnosed with COPD during the total observation period, there were no significant differences in the development of COPD between the seropositive group (37 patients, 2.0\%) and the seronegative group (39 patients, $2.2 \%)(\mathrm{P}=0.728)$.

\section{The impact of $H$. pylori infection on the rate of decline in lung function}

When comparing the annual decline rates of the mean FVC and $\mathrm{FEV}_{1}$ according to the seropositivity of $H$. pylori, we found no significant difference in the annual decline rate of the mean FVC between the two groups $(35.38 \pm 0.90 \mathrm{~mL} /$ year for seronegative group vs. $34.34 \pm 0.81 \mathrm{~mL} /$ year for seropositive group, $\mathrm{P}=0.389$ ) (Table 2, Figure 1) or in the annual decline rate of the mean $\mathrm{FEV}_{1}(39.23 \pm 0.75 \mathrm{~mL} /$ year in seronegative group $v s .37 .49 \pm 0.68 \mathrm{~mL} /$ year in the seropositive group, $\mathrm{P}=0.086$ ). To minimize the limitation of H. pylori-specific IgG in identifying recent infection, we also performed subgroup analyses in 143 patients with recent seroconversion to seropositive status during the observation period. Nevertheless, there were no differences in the mean FVC $(40.05 \pm 2.54 \mathrm{~mL} /$ year $)$ or $\mathrm{FEV}_{1}(34.62 \pm 3.13 \mathrm{~mL} /$ year $)$ rates of decline (Table 3$)$.

\section{The impact of eradication on the decline of lung function}

A total of 460 of the 1,849 seropositive patients (24.9\%) received antibiotics and PPI for $H$. pylori eradication therapy. The annual mean FVC decline rate $(34.51 \pm 1.41 \mathrm{~mL} /$ year $)$ did not significantly differ from that of subjects without eradication treatment $(34.26 \pm 0.99 \mathrm{~mL} /$ per year, $\mathrm{P}=0.603)$ (Table 4). Also, there was no significant difference in the annual decline rate of $\mathrm{FEV}_{1}$ between the two groups $(37.29 \pm 1.15 \mathrm{~mL} /$ year for $H$. pylori treated group $v s$. $37.37 \pm 0.81 \mathrm{~mL} /$ year for the group without $H$. pylori treatment $(\mathrm{P}=0.954)$ (Figure 2).

\section{Discussion}

This large-scaled longitudinal analysis demonstrated that $H$. pylori infection did not affect the annual decline rates of $\mathrm{FEV}_{1}$ or FVC, and infection was not associated with the incidence of COPD. Although several reports indicate that $H$. pylori infection increases the risk of COPD, the present study, in 
Table 1 Baseline characteristics of study population

\begin{tabular}{|c|c|c|c|}
\hline Characteristics & $\begin{array}{l}\text { H. pylori sero-negative group } \\
\qquad(\mathrm{n}=1,770)\end{array}$ & $\begin{array}{l}\text { H. pylori sero-positive group } \\
\qquad(\mathrm{n}=1,849)\end{array}$ & $\mathrm{P}$ \\
\hline Age (year), mean \pm SE & $48.26( \pm 6.54)$ & $48.87( \pm 6.37)$ & 0.004 \\
\hline Sex (male), n (\%) & $1,029(58.1)$ & $1,197(64.7)$ & $<0.001$ \\
\hline Body mass index $\left(\mathrm{kg} / \mathrm{m}^{2}\right)$, mean $\pm \mathrm{SE}$ & $23.32( \pm 2.83)$ & $23.61( \pm 2.77)$ & 0.002 \\
\hline Ex-smoker, n (\%) & $545(30.9)$ & $633(34.3)$ & \\
\hline Current smoker, n (\%) & $295(16.7)$ & $307(16.6)$ & \\
\hline Smoking amount (pack-year), mean \pm SE & $9.12( \pm 14.03)$ & $10.08( \pm 15.08)$ & \\
\hline \multicolumn{4}{|l|}{ Lung function, mean \pm SE } \\
\hline FVC, L & $3.82( \pm 0.82)$ & $3.90( \pm 0.82)$ & 0.003 \\
\hline FVC, \% predicted & $96.32( \pm 10.80)$ & $96.99( \pm 10.90)$ & 0.065 \\
\hline $\mathrm{FEV}_{1} / \mathrm{FVC}, \%$ & $81.80( \pm 6.5)$ & $81.41( \pm 6.48)$ & 0.067 \\
\hline COPD, n (\%) & $48(2.7)$ & $47(2.5)$ & 0.756 \\
\hline Follow-up period, mean year & $5.69( \pm 0.06)$ & $6.28( \pm 0.06)$ & $<0.001$ \\
\hline $\mathrm{WBC}$, mean $\pm \mathrm{SE}$ & $5,286( \pm 35.9)$ & $5,658( \pm 35.0)$ & $<0.001$ \\
\hline Eosinophil count/ $\mathrm{LL}$ & $153( \pm 3.42)$ & $155( \pm 3.44)$ & 0.7160 \\
\hline
\end{tabular}

Table 2 The annual decline rate of lung function, adjusted by age, sex, height, and amount of smoking in pack-year

\begin{tabular}{lccc}
\hline Lung function index & H. pylori sero-negative group $(\mathrm{n}=1,770)$ & H. pylori sero-positive group $(\mathrm{n}=1,849)$ & $\mathrm{P}$ \\
\hline FEV ${ }_{1}, \mathrm{~mL} /$ year & $-39.23( \pm 0.751)$ & $-37.49( \pm 0.676)$ & 0.086 \\
FVC, mL/year & $-35.38( \pm 0.896)$ & $-34.34( \pm 0.807)$ & 0.389 \\
\hline
\end{tabular}

conjunction with our previous study, indicated that $H$. pylori infection was not associated with COPD (9). Additionally, the eradication of $H$. pylori did not affect the rate of decreased in lung function and the development of COPD.

This study presents some strengths compared with previous reports on the association between $H$. pylori infection and COPD. First, this was a large-scale population cohort study with a long follow-up period in a high prevalence area of $H$. pylori infection. Secondly, the study population, GINIE cohort, consisted of a health screening population and followed an organized system that resulted in a low dropout rate. Numerous publications have already demonstrated the data quality of the study population. This suggests that the longitudinal data in this study may contain fewer biases such as the high drop-out rates seen in retrospective cohort studies. Furthermore, the effects of the eradication treatment of $H$. pylori infection were examined on main outcomes. To date, no studies have confirmed whether the rate of lung function is affected with $H$. pylori eradication.

As the prevalence of $H$. pylori infection varies by region, the effects of $H$. pylori infection on extra-gastric diseases 

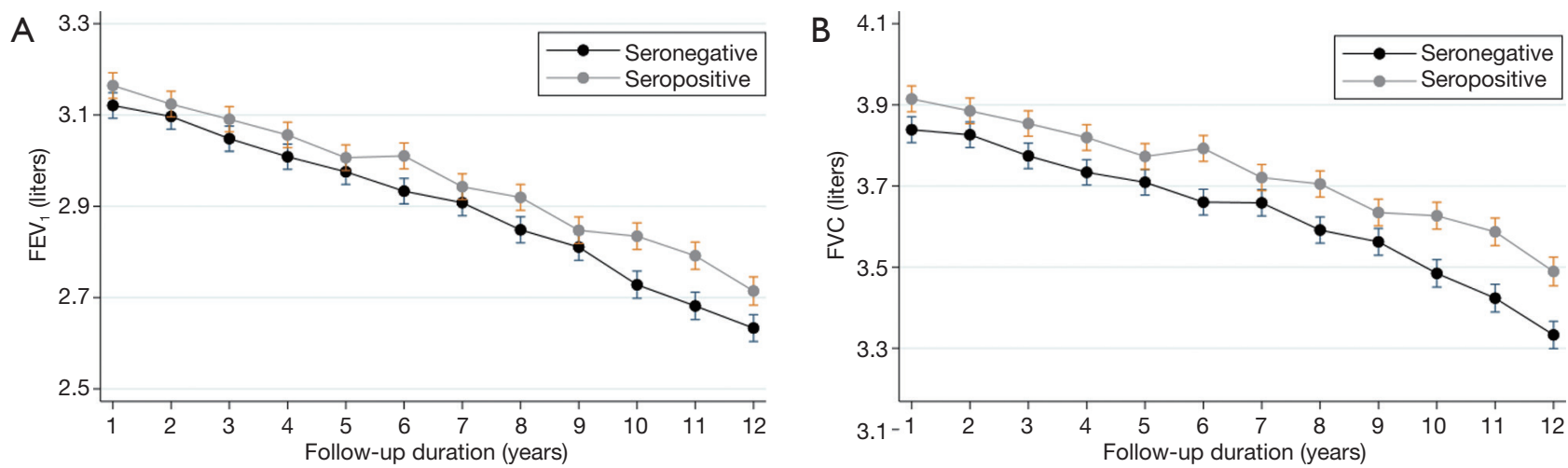

Figure 1 The annual rate of lung function decline. (A) Decline in $\mathrm{FEV}_{1}$ for 12 years; $39.23 \pm 0.75 \mathrm{~mL} / \mathrm{year}$ in seronegative group $v s$. $37.49 \pm 0.68 \mathrm{~mL} /$ year in the seropositive group, $\mathrm{P}=0.086$. (B) Decline in FVC for 12 years; $35.38 \pm 0.90 \mathrm{~mL} /$ year for seronegative group vs $34.34 \pm 0.81 \mathrm{~mL} /$ year for seropositive group, $\mathrm{P}=0.389$.

Table 3 The annual decline rates of lung function in patients with positive seroconversion suggesting recent infection of $H$. pylori

\begin{tabular}{lcc}
\hline Lung function index & $\begin{array}{c}\text { Subjects with alleged } H . \text { pylori infection } \\
(\mathrm{n}=1,849)\end{array}$ & $\begin{array}{c}\text { Subjects with newly positive } \\
\text { seroconversion }(\mathrm{n}=143)\end{array}$ \\
\hline $\mathrm{FEV}_{1}, \mathrm{~mL} /$ year & $-37.32( \pm 0.66)$ & $-40.05( \pm 2.54)$ \\
$\mathrm{FVC}, \mathrm{mL} /$ year & $-34.36( \pm 0.81)$ & $-34.62( \pm 3.13)$ \\
\hline
\end{tabular}

Table 4 The annual decline rates of lung function according to medical eradication for $H$. pylori during follow-up period among the patients with sero-positivity to H. pylori Ig G

\begin{tabular}{|c|c|c|c|}
\hline Lung function index & Subjects treated for $H$. pylori $(\mathrm{n}=460)$ & $\begin{array}{l}\text { Subjects without treatment for H. pylori } \\
\qquad(\mathrm{n}=1,389)\end{array}$ & $P$ \\
\hline $\mathrm{FEV}_{1}, \mathrm{~mL} /$ year & $-37.29( \pm 1.15)$ & $-37.37( \pm 0.81)$ & 0.953 \\
\hline FVC, mL/year & $-34.508( \pm 1.41)$ & $-34.26( \pm 0.99)$ & 0.886 \\
\hline
\end{tabular}

are also expected to be variable. For example, the mean prevalence of $H$. pylori infection in the USA was $35 \%$ (range, $22-48 \%$ ) between 1990 and 2006 with no increasing or decreasing infection rates over this time period (13). In this study, the prevalence of $H$. pylori infection was $51.1 \%$, similar to previous studies conducted in Korea that reported a prevalence of $H$. pylori infection from 50 to $60 \%(14,15)$.

As for the physical characteristics of study population compared with previous reports (16-18), even though $H$. pylori seropositive group showed statistically higher values in age, BMI, and height, the absolute difference in each variable seems to be too small to suggest clinical significance in general population and some studies reported that the effect of $H$. pylori infection on height disappeared after a multivariate analysis $(16,17,19,20)$. Male predominance in the H. pylori seropositive group appeared in this study, similar to several large sample studies that have reported that men were more positive on serum or biopsies than women $(21,22)$.

Currently, Sze et al. reported the most extensive study including patients with COPD in a lung health study (LHS) on the relationship between $H$. pylori seropositivity and COPD (7). With the observation over 11 years, they showed that the absolute $\mathrm{FEV}_{1}$ value in seropositive patients was lower than that in seronegative patients even though the relationship disappeared when the $\mathrm{FEV}_{1}$ (\% predicted) value was used. The authors asserted that $H$. pylori infection was associated with reduced lung function related to the effects of the bacterium on lung growth earlier in life and systemic inflammation. Contrary to the report, our study 

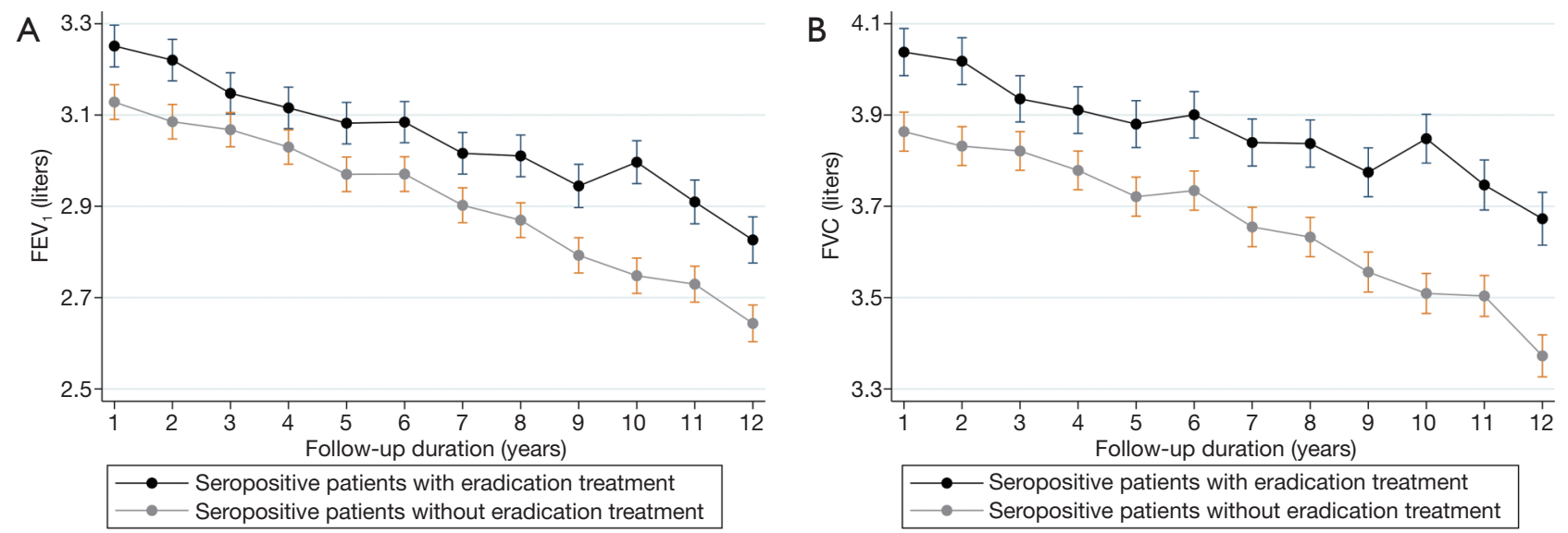

Figure 2 The annual decline rate of lung function depending on eradication of $H$. pylori. (A) Decline in $\mathrm{FEV}_{1}$ for 12 years; $37.29 \pm 1.15 \mathrm{~mL} / \mathrm{year}$ for $H$. pylori treated group vs. $37.37 \pm 0.81 \mathrm{~mL} /$ year for the group without $H$. pylori treatment $(\mathrm{P}=0.954)$. (B) Decline in FVC for 12 years; $34.51 \pm 1.41 \mathrm{~mL} /$ year for $H$. pylori treated group vs. $34.26 \pm 0.99 \mathrm{~mL} /$ per year for the group without $H$. pylori treatment $(\mathrm{P}=0.603)$.

did not show any significant difference in the rate of lung function (both absolute value and \% predicted value) in the seropositive population. Furthermore, although not statistically significant, a slower rate of decline in $\mathrm{FEV}_{1}$ was observed in the seropositive group $(\mathrm{P}=0.08)$.

However, we should consider some different aspects in both studies. First, our study enrolled a healthier general population. The baseline lung function was higher in this population and only $2.6 \%$ of total subjects had COPD at the enrollment (mean FEV1 $2.54 \mathrm{~L}, 83.87 \%$ predicted), while the analysis report of LHS targeted mild to moderate COPD patients (mean $\mathrm{FEV}_{1} 2.80 \mathrm{~L}, 78 \%$ predicted) (7). Therefore, even the impacts of $H$. pylori infection may present, the influence on the total lung function may be limited or negligible in a healthier population than in established COPD. Another point is the difference in seropositivity in the study population. As shown in this study, the seropositivity of $H$. pylori was so prevalent that more than half of the population had a current or past infection of $H$. pylori, a rate much higher than the $18 \%$ reported in the LHS study.

The induction of systemic inflammation by $H$. pylori was proposed as the mechanism underlying the association between COPD and $H$. pylori infections. The infection can trigger a low-grade inflammatory state, including the type 1 helper immune response and suppression of the type $2 \mathrm{~T}$ helper cell immune response (23). This polarized T-helper cell response has explained the relatively low prevalence of asthma and the high prevalence of COPD in this seropositive population. In addition, recently, studies are focusing on the effects of $H$. pylori on the intestinal microbiome (24). However, in a high prevalence area, the inflammation related to $H$. pylori may present such a weak or common signal that it may not be a major contributor to reduce lung function.

In this study, for the first time, we evaluated the effects of eradication of $H$. pylori on changes in lung function. However, the effect was not significant. This may suggest that the other factors including subsequent inflammation, are more critical rather than the initial $H$. pylori infection itself. However, as the main results were negative and the detailed inflammatory markers except CRP were not available in this study, further analysis and interpretation could not be performed.

Despite the interesting findings of this study, some limitations should also be considered. First, we considered the limitation of seropositivity in detecting current infection of $H$. pylori and the discrepancy with results using endoscopic biopsy samples $(9,25)$. Unfortunately, endoscopic biopsy results of $H$. pylori were not available in the current study. Second, the study population may be relatively young to analyze more COPD patients considering that the prevalence of COPD increases with age (26) and other association studies $(10,27)$.

\section{Conclusions}

In the present study using health screening general population, seropositivity defined infection or the eradication treatment of $H$. pylori were not associated with the decline of 
lung function or progression to COPD. H. pylori infection may not be a significant factor contributing to deteriorating lung function.

\section{Acknowledgments}

Funding: None.

\section{Footnote}

Reporting Checklist: The authors have completed the STROBE reporting checklist. Available at http://dx.doi. org/10.21037/apm-20-850

Data Sharing Statement: Available at http://dx.doi. org/10.21037/apm-20-850

Conflicts of Interest: All authors have completed the ICMJE uniform disclosure form (available at http://dx.doi. org/10.21037/apm-20-850). The authors have no conflicts of interest to declare.

Ethical Statement: The authors are accountable for all aspects of the work in ensuring that questions related to the accuracy or integrity of any part of the work are appropriately investigated and resolved. The present study was approved by the Institutional review board (IRB No. H-1804-028-934) and was in accordance with the 1964 and later modifications of the Helsinki declaration (as revised in 2013) on the use of human subjects for research. Written informed consent was obtained from the patient before GENIE cohort registration.

Open Access Statement: This is an Open Access article distributed in accordance with the Creative Commons Attribution-NonCommercial-NoDerivs 4.0 International License (CC BY-NC-ND 4.0), which permits the noncommercial replication and distribution of the article with the strict proviso that no changes or edits are made and the original work is properly cited (including links to both the formal publication through the relevant DOI and the license). See: https://creativecommons.org/licenses/by-nc-nd/4.0/.

\section{References}

1. Mendall MA, Goggin PM, Molineaux N, et al. Relation of Helicobacter pylori infection and coronary heart disease. Heart 1994;71:437-9.
2. Ražuka-Ebela D, Giupponi B, Franceschi F. Helicobacter pylori and extragastric diseases. Helicobacter 2018;23:e12520.

3. Franceschi F, Gasbarrini A, Polyzos SA, et al. Extragastric diseases and Helicobacter pylori. Helicobacter 2015;20:40-6.

4. Franceschi F, Gasbarrini A. Helicobacter pylori and extragastric diseases. Best Pract Res Clin Gastroenterol 2007;21:325-34.

5. Roussos A, Tsimpoukas F, Anastasakou E, et al. Helicobacter pylori seroprevalence in patients with chronic bronchitis. J Gastroenterol 2002;37:332-5.

6. Siva R, Birring SS, Berry M, et al. Peptic ulceration, Helicobacter pylori seropositivity and chronic obstructive pulmonary disease. Respirology 2013;18:728-31.

7. Sze MA, Chen YWR, Tam S, et al. The relationship between Helicobacter pylori seropositivity and COPD. Thorax 2015;70:923-9.

8. Fullerton D, Britton JR, Lewis SA, et al. Helicobacter pylori and lung function, asthma, atopy and allergic disease-a population-based cross-sectional study in adults. Int J Epidemiol 2008;38:419-26.

9. Lee HY, Kim JW, Lee JK, et al. Association between Helicobacter pylori seropositivity and mild to moderate COPD: clinical implications in an Asian country with a high prevalence of $\mathrm{H}$. pylori. Int J Chron Obstruct Pulmon Dis 2016;11:2055-62.

10. Wang F, Liu J, Zhang Y, et al. Association of Helicobacter pylori infection with chronic obstructive pulmonary disease and chronic bronchitis: a meta-analysis of 16 studies. Infect Dis (Lond) 2015;47:597-603.

11. Park B, Koo SM, An J, et al. Genome-wide assessment of gene-by-smoking interactions in COPD. Sci Rep 2018;8:9319.

12. Graham BL, Steenbruggen I, Miller MR, et al. Standardization of Spirometry 2019 Update. An Official American Thoracic Society and European Respiratory Society Technical Statement. Am J Respir Crit Care Med 2019;200:e70-e88.

13. Nagy P, Johansson S, Molloy-Bland M. Systematic review of time trends in the prevalence of Helicobacter pylori infection in China and the USA. Gut Pathog 2016;8:8.

14. Pan KF, Zhang L, Gerhard M, et al. A large randomised controlled intervention trial to prevent gastric cancer by eradication of Helicobacter pylori in Linqu County, China: baseline results and factors affecting the eradication. Gut 2016;65:9-18.

15. Lim SH, Kwon JW, Kim N, et al. Prevalence and 
risk factors of Helicobacter pylori infection in Korea: nationwide multicenter study over 13 years. BMC

Gastroenterol 2013;13:104.

16. Moayyedi P, Forman D, Duffett S, et al. The association between Helicobacter pylori infection and adult height. Eur J Epidemiol 2005;20:455-65.

17. Dore MP, Pes GM, Sferlazzo G, et al. Role of Helicobacter pylori infection in body height of adult dyspeptic patients. Helicobacter 2016;21:575-80.

18. Sood MR, Joshi S, Akobeng AK, et al. Growth in children with Helicobacter pylori infection and dyspepsia. Arch Dis Child 2005;90:1025-8.

19. Muhsen K, Goren S, Cohen D. H elicobacter pylori Infection in Early Childhood and Growth at School Age. Helicobacter 2015;20:410-7.

20. Kocaoglu C, Ozel A, Cayci M, et al. Effect of long-term Helicobacter pylori infection on growth of children: a cohort study. World J Pediatr 2016;12:196-201.

21. Huang RG, Xiao HL, Zhou B, et al. Serum pepsinogen levels are correlated with age, sex and the level of Helicobacter pylori infection in healthy individuals. Am J
Med Sci 2016;352:481-6.

22. Yang $Y$, Xiong W, Wang S, et al. Factors associated with detection of Helicobacter pylori in gastric biopsies: a casecontrol study of 396 biopsies. Appl Immunohistochem Mol Morphol 2018;26:345-50.

23. Franceschi F, Zuccalà G, Roccarina D, et al. Clinical effects of Helicobacter pylori outside the stomach. Nat Rev Gastroenterol Hepatol 2014;11:234-42.

24. Bravo D, Hoare A, Soto C, et al. Helicobacter pylori in human health and disease: Mechanisms for local gastric and systemic effects. World J Gastroenterol 2018;24:3071-89.

25. Mahmood S, Hamid A. Comparison between invasive and noninvasive tests in diagnosis of Helicobacter pylori infection. Pak J Biol Sci 2010;13:509-12.

26. Available online: http://oldrf.org/Kr/Home/Download? path $=$ \% 2FData \%2FPublication \%2FDownload \%2F\% 2F84-87_OLD08.pdf\&filename=84-87_OLD08.pdf

27. Peng $\mathrm{YH}, \mathrm{Chen} \mathrm{CK}, \mathrm{Su} \mathrm{CH}$, et al. Increased risk of chronic obstructive pulmonary disease among patients with Helicobacter pylori infection: a population-based cohort study. Clin Respir J 2017;11:558-65.
Cite this article as: Lee HY, Kang HR, Lee JK, Heo EY, Choi $\mathrm{SH}, \mathrm{Kim}$ DK. The effect of Helicobacter pylori infection on the decline of lung function in a health screening population. Ann Palliat Med 2020;9(5):3115-3122. doi: 10.21037/apm-20-850 